\title{
GAMBARAN KARAKTERISTIK IBU HAMIL YANG MENGALAMI ANEMIA DI KLINIK MITRA DELIMA KECAMATAN BANJARSARI KABUPATEN CIAMIS
}

\section{DESCRIPTION OF CHARACTERISTICS OF PREGNANT MOTHERS WITH ANEMIA AT MITRA DELIMA CLINIC, BANJARSARI DISTRICT, CIAMIS REGENCY}

\author{
Elsa Salsabila Amalia Nisa ${ }^{1^{*}}$, Arifah Septiane ${ }^{2}$, Siti Fatimah ${ }^{3}$ \\ ${ }^{1,2}$ Program Studi D-III Kebidanan, Fakultas Ilmu Kesehatan, Universitas Galuh \\ Jalan R.E Martadinata No.10 Ciamis 46213, Indonesia \\ *E-mail corresponding: salsabilaamalianisaelsa@gmail.com \\ (Diterima: Maret 2021; disetujui April 2021; dipublish Mei 2021)
}

\begin{abstract}
ABSTRAK
Data WHO menunjukkan bahwa sekitar 30\% ibu hamil di Indonesia mengalami anemia. Faktor yang menyebabkan anemia diantaranya karakteristik ibu dan pengetahuan. Tujuan umum penelitian ini untuk mengetahui karakteristik ibu hamil yang mengalami anemia di Klinik Mitra Delima Kecamatan Banjarsari Kabupaten Ciamis. Jenis penelitian yang digunakan adalah deskriptif kuantitatif. Populasi pada penelitian ini adalah seluruh ibu hamil yang mengalami anemia di Klinik Mitra Delima Kecamatan Banjarsari Kabupaten Ciamis yang berdasarkan data periode 10 April - 15 Mei 2021 sebanyak 64 orang Penentuan sampel dengan total sampling karena jumlah populasi $<100$ sehingga sampel pada penelitian ini adalah 64 responden. Hasil Penelitian menunjukkan bahwa sebagian besar dari ibu hamil di Klinik Mitra Delima Kecamatan Banjarsari Kabupaten Ciamis berumur beresiko yaitu 35 orang (54,7\%), mempunyai anak $<2$ (paritas primi) yaitu 37 orang $(57,8 \%)$, mempunyai jarak kehamilan $<2$ tahun yaitu 39 orang $(60,9 \%)$, berpendidikan dasar yaitu 35 orang $(54,7 \%)$, bekerja yaitu 35 orang $(54,7 \%)$, mengalami KEK yaitu 34 orang $(53,1 \%)$, tidak pernah infeksi yaitu 36 orang $(56,3 \%)$, berpengetahuan kurang yaitu 34 orang $(53,1 \%)$. Bidan agar lebih intensif dalam program penurunan angka anemia pada ibu hamil, baik dalam perberian tablet Fe 90 tablet maupun pemeriksaan haemoglobin.
\end{abstract}

Kata kunci: Karakteristik, Ibu Hamil, Anemia

\begin{abstract}
WHO data shows that about $30 \%$ of pregnant women in Indonesia are anemic. Factors that cause anemia include maternal characteristics and knowledge. The general purpose of this research is to find out characteristics of pregnant women with anemia at Mitra Delima Clinic, Banjarsari District, Ciamis Regency. The type of research used is descriptive quantitative. The population in this study were all pregnant women who experienced anemia at Mitra Delima Clinic, Banjarsari District, Ciamis Regency based on data for the period 10 April - 15 May 2021 as many as 64 people. Determination of the sample with total sampling because the population $<100$ so that the sample in this study was 64 respondents . The results showed that most of the pregnant women at Mitra Delima Clinic, Banjarsari District, Ciamis Regency were at risk of 35 people (54.7\%), had children $<2$ (primary parity) that was 37 people $(57.8 \%$ ), had pregnancy intervals $<2$ years, namely 39 people $(60.9 \%)$, basic education, namely 35 people $(54.7 \%)$, working 35 people (54.7\%), experiencing SEZ, namely 34 people (53.1\%), never infections were 36 people $(56.3 \%)$, lack of knowledge were 34 people $(53.1 \%)$. Midwives to be more intensive in the program to reduce anemia rates in pregnant women, both in giving 90 tablets of Fe tablets and checking for hemoglobin.
\end{abstract}

Keywords: Characteristics, Pregnant Women, Anemia 


\section{PENDAHULUAN}

Beberapa faktor risiko yang meningkatkan kejadian anemia adalah primigravida (hamil pertama kali), multigravida (kehamilan lebih dari sekali), umur ibu dibawah 20 dan diatas 35 tahun. Pada kehamilan, sel darah merah dan hemoglobin meningkat secara perlahan pada pertengahan awal periode kehamilan, kemudian pertengahan akhir kehamilan terjadi peningkatan sel darah merah, konsentrasi hemoglobin serta hematokrit masih berlanjut dan kembali normal setelah 6 minggu masa kuning. Ibu hamil yang bekerja perlu menambah konsumsi gizinya agar terhindar dari anemia (Kozuma, 2016).

Data WHO menunjukkan bahwa sekitar 30\% ibu hamil di Indonesia mengalami anemia. Angka ini lebih tinggi jika dibandingkan dengan Negara lain di Asia Tenggara seperti Malaysia (27\%), Singapura (28\%), dan Vietnam (23\%). Menurut data Riset Kesehatan Dasar (Riskesdas) pada tahun 2018, prevalensi anemia pada ibu hamil di Indonesia sebesar 37,1\%. Provinsi Jawa Barat merupakan provinsi yang berkontribusi besar terhadap tingginya AKI di Indonesia. Bina Pelayanan Kesehatan Dinas Kesehatan provinsi Jawa Barat mengatakan AKI pada tahun 2020 sebanyak 312/100.000 kelahiran hidup (Dinas Kesehatan Jawa Barat, 2020).

Data Dinkes Ciamis menyatakan AKI di Kota Ciamis pada 2017 sebesar 16 kasus, sementara AKB di Kota Ciamis sebanyak 73/11.364 kelahiran hidup (Dinkes Ciamis, 2019). Profil kesehatan Ciamis tahun 2019 melaporkan ibu hamil yang mengalami anemia yaitu angka tertinggi di wilayah kerja puskesmas Banjarsari 257 orang, Pamarican 245 orang, dan terendah di Kecamatan Ciamis 134 orang sedangkan bayi yang lahir dengan Bayi Berat Lahir Rendah (BBLR) angka tertinggi berada di wilayah kerja Puskesmas Banjarsari 57 bayi.

\section{METODE PENELITIAN}

Jenis penelitian yang digunakan adalah deskriptif kuantitatif. Populasi pada penelitian ini adalah seluruh ibu hamil yang mengalami anemia di Klinik Mitra Delima Kecamatan Banjarsari Kabupaten Ciamis yang berdasarkan data periode 10 April - 15 Mei 2021 sebanyak 64 orang. Jumlah sampel dalam penelitian ini menggunakan sampling jenuh atau total sampling karena jumlah populasi $<100$ sehingga sampel pada penelitian ini adalah 64 responden. Variabel dalam penelitian ini adalah gambaran karakteristik ibu hamil yang mengalami anemia Klinik Mitra Delima dengan sub variable Umur Ibu, Paritas, Pendidikan, Pekerjaan, Jarak Kehamilan, Status Gizi, Penyakit Infeksi dan pengetahuan. Definisi operasional variabel adalah pengertian variabel (yang diungkap dalam definisi konsep) tersebut, secara operasional, secara praktik, secara nyata dalam lingkup obyek penelitian/obyek yang diteliti (Notoatmodjo, 2013) Instrumen yang digunakan dalam penelitian ini adalah lembar ceklis dan kuesioner . Jenis data yang digunakan dalam penelitian ini adalah Data Primer data yang digunakan bersumber dari hasil wawancara dan kuesioner yang dikembangkan guna mendapat hasil yang dibutuhkan peneliti. Untuk keefektifannya pembagian kuesioner 
dibantu oleh kader/bidan, dan terlebih dahulu dijelaskan cara pengisiannya. Sedangkan data sekunder adalah data diperoleh dari buku KIA dan kohort ibu hamil.

\section{HASIL PENELITIAN DAN \\ PEMBAHASAN}

\section{Hasil Penelitian}

Tabel 1

Distribusi Frekuensi Umur Ibu Hamil di Klinik Mitra Delima Kecamatan Banjarsari Kabupaten Ciamis

\begin{tabular}{l|c|c}
\hline Umur & F & \% \\
\hline Beresiko & 35 & 54.7 \\
\hline Tidak Beresiko & 29 & 45.3 \\
\hline Total & $\mathbf{6 4}$ & $\mathbf{1 0 0}$ \\
\hline
\end{tabular}

Hasil dari tabel menunjukan bahwa dari 64 responden umur ibu beresiko sebesar 35 responden $(54,7 \%)$ dan yang tidak beresiko sebesar 29 orang (45.3\%)

\section{Tabel 2}

Distribusi Frekuensi Paritas Ibu Hamil di Klinik Mitra Delima Kecamatan Banjarsari Kabupaten Ciamis

\begin{tabular}{lcc}
\multicolumn{1}{c}{ Paritas } & F & \% \\
\hline Belum Punya & 0 & 0 \\
Anak & 37 & 57.8 \\
>2 Anak & 27 & 42.2 \\
$<2$ Anak & $\mathbf{6 4}$ & $\mathbf{1 0 0}$
\end{tabular}

Hasil penelitian menunjukan bahwa dari 64 responden, yang belumpunya anaktidak ada, yang memiliki lebih dari 2 anak sebesar 37 responden (57.8\%) dan yang kurang dari dua anak 27 responden (42.2\%)
Tabel 3

Distribusi Frekuensi Jarak Kelahiran Ibu Hamil di Klinik Mitra Delima Kecamatan Banjarsari Kabupaten Ciamis

\begin{tabular}{lcc} 
Jarak Kelahiran & F & \% \\
\hline Belum & 0 & 0 \\
Melahirkan & & \\
$<2$ Tahun & 39 & 60.9 \\
$>2$ Tahun & 25 & 39.1 \\
\hline Total & $\mathbf{6 4}$ & $\mathbf{1 0 0}$
\end{tabular}

Dari tabel di atas menunjukan bahwa dari 64 responden, yang belum pernahmelahirkan tidak ada, yang memiliki lebih dari 2 tahun jarak melahirkan sebesar 39 responden $(60,9 \%)$ dan yang mealhirkan lebih dari dua tahun anak 25 responden $(39,1 \%)$

Tabel 4

Distribusi Frekuensi Pendidikan Ibu Hamil di Klinik MitraDelima Kecamatan Banjarsari Kabupaten Ciamis

\begin{tabular}{lcc} 
Pendidikan & F & \% \\
\hline Dasar & 35 & 54.7 \\
Menengah & 29 & 45.3 \\
Tinggi & 0 & 0 \\
\hline Total & $\mathbf{6 4}$ & $\mathbf{1 0 0}$
\end{tabular}

Dari tabel di atas menunjukan bahwa dari 64 responden, yang memiliki pendidikan dasar 35 responden (54,7\%), yang memiliki pendidikan menengah 29 responden $(45,3 \%)$ dan yang memiliki pendidikan tinggi tidak ada.

Tabel 5

Distribusi Frekuensi Pekerjaan Ibu Hamil di Klinik Mitra Delima Kecamatan Banjarsari Kabupaten Ciamis

\begin{tabular}{lcc} 
Pekerjaan & F & \% \\
\hline Bekerja & 35 & 54.7 \\
Tidak Bekerja & 29 & 45.3 \\
\hline Total & $\mathbf{6 4}$ & $\mathbf{1 0 0}$
\end{tabular}


Dari tabel di atas menunjukan bahwa dari 64 responden, yang ibubekerja sebanyak 35 (54,7\%) responden, dan tidak bekerja 29 $(45,3 \%)$ responden.

Tabel 6

Distribusi Frekuensi Status Gizi Ibu Hamil di Klinik Mitra Delima Kecamatan Banjarsari Kabupaten Ciamis

\begin{tabular}{lcc} 
Status Gizi & F & $\mathbf{\%}$ \\
\hline KEK & 34 & 53.1 \\
Tidak KEK & 30 & 46.9 \\
\hline Total & $\mathbf{6 4}$ & $\mathbf{1 0 0}$
\end{tabular}

Dari tabel di atas menunjukan bahwa dari 64 responden, yang statusgizi KEK sebanyak $34(53,1)$ responden, yangtidak KEK 30 (46,9\%) responden.

\section{Tabel 7}

Distribusi Frekuensi Penyakit Infeksi Ibu Hamil di Klinik Mitra Delima Kecamatan Banjarsari Kabupaten Ciamis

\begin{tabular}{lcc}
$\begin{array}{c}\text { Penyakit } \\
\text { Infeksi }\end{array}$ & F & \% \\
\hline Tidak Pernah & 28 & 43.8 \\
Pernah & 36 & 56.3 \\
\hline Total & $\mathbf{6 4}$ & $\mathbf{1 0 0}$
\end{tabular}

Dari tabel di atas menunjukan bahwa dari 64 responden, yang tidak pernah mengalami penyakit infeksi 28 responden (43,8\%), yang pernah mengalamipenyakit infeksi $36(56,3 \%)$ responden.

\section{Tabel 8}

Distribusi Frekuensi Pengetahuan Ibu Hamil tentang Anemia di Klinik Mitra Delima Kecamatan Banjarsari Kabupaten Ciamis

\begin{tabular}{llcc} 
No & Pengetahuan & F & \% \\
\hline 1 & Baik & 3 & 4.7 \\
2 & Cukup & 27 & 42.2 \\
3 & Kurang & 34 & 53.1 \\
\hline & Total & 64 & $100 \%$
\end{tabular}

Dari tabel di atas menunjukan bahwa dari 64 responden, yang memiliki pengetahuan baik sebanyak 3 responden (4,7\%, yang memiliki pengetahuan cukup 27 responden (42,2\%), yang memiliki pengetahuan kurang 34 responden $(53,1 \%)$.

\section{PEMBAHASAN}

Hasil penelitian menunjukkan bahwa sebagian besar umur dari ibu hamil di Klinik Mitra Delima Kecamatan Banjarsari Kabupaten Ciamis berumur beresiko yaitu 35 orang $(54,7 \%)$. Umur yang ideal untuk yang hamil yaitu pada umur 20-35 tahun dan pada umur tersebut kurang beresiko komplikasi kehamilan serta memiliki reproduksi yang sehat.Hal ini terkait dengan 8 kondisi biologis dan psikologis saat ibu hamil sebaliknya jika umur $<20$ tahun termasuk beresiko anemia sebab perkembangan biologisnya belum optimal. Selain itu, kehamilan pada kelompok umur diatas 35 tahun merupakan kehamilan yang beresiko tinggi. Ibu hamil dengan usia yang terlalu tua juga rentan terjadinya anemia. (Manuaba, 2013).

Penelitian menunjukkan bahwa sebagian besar dari ibu hamil di Klinik Mitra Delima Kecamatan Banjarsari Kabupaten Ciamis mempunyai anak $>2$ yaitu 37 orang $(57,8 \%)$. Hal ini tidak sesuai dengan teori bahwa setelah kehamilan yang ketiga resiko anemia meningkat, hal ini disebabkan karena pada kehamilan yang berulang menimbulkan kerusakan pada pembuluh darah dan dinding uterus yang biasanya mempengaruhi sirkulasi nutrisi ke janin. Setiap kali wanita melahirkan, jumlah zat besi yang hilang diperkirakan sebesar 250mg (Wijayanto, 2018). 
Sebagian besar dari ibu hamil di Klinik

Mitra Delima Kecamatan Banjarsari Kabupaten Ciamis mempunyai jarak kehamilan $<2$ tahun yaitu 39 orang $(60,9 \%)$. Setiap ibu hamil harus memiliki jarak karna jarak kehamilan mempengaruhiu status dan kebutuhan zat besi selama kehamilan terutama pada ibu hamil yang mengalami kekurangan cadangan besi pada awal kehamilan dan pada saat persalinan ibu hamil akan banyak kehilangan zat besi melalui perdarahan saat persalinan.

Dari hasil penelitian menunjukkan bahwa sebagian besar dari ibu hamil di Klinik Mitra Delima Kecamatan Banjarsari Kabupaten Ciamis berpendidikan dasar yaitu 35 orang $(54,7 \%)$. Pendidikan sangat berpengaruh terhadap prilaku seseorang serta mempengaruhi sesorang untuk menyelesaikan masalah atau memberi solusi kepada kehidupannya. Pendidikan sangatlah penting untuk kehidupan sehari sehari karna pendidikan sesorang dapat menerima gagasan baru. Demikian ibu yang memiliki pendidikan tinggi lebih memeriksakan kesehatan yang teratur dan menjaga diri dan anaknnya yang dikandung dengan ibu yang berpendidikan tinggi akan memeriksakan kehamilannya secara teratur demi menjaga keadaan kesehatan dirinya dan anak dalam kandungannya (Walyani,2015).

Klinik Mitra Delima Kecamatan Banjarsari Kabupaten Ciamis ibuyang bekerja yaitu 35 orang (54,7\%). Hasil penelitian ini sesuai dengan teori Ditjen Bina Gizi Masyarakat (2012) yang mengatakan bahwa tingginya aktifitas fisik dan terbatasnya waktu yang dimiliki untuk mengkonsumsi makanan menyebabkan asupan makanan menjadi tidak tercukupi dan dapat mempengaruhi asupan zat besi dalam pengelolahan hemoglobin tidak dapat memproduksi dengan norma

Hasil penelitian menunjukkan bahwa sebagian besar dari ibu hamil di Klinik Mitra Delima Kecamatan Banjarsari Kabupaten Ciamis mengalami KEK yaitu 34 orang $(53,1 \%)$. Menurut teori yang dikemukakan oleh Departemen Gizi dan Kesehatan Masyarakat (2013), bahwa anemia sangat dipengaruhi oleh status gizi seseorang. Anemia dapat disebabkan oleh gizi yang kurang . LILA mencerminkan cadangan energi, sehingga dapat mencerminkan kekurangan energi dan kalori (KEK) pada ibu WUS dan ibu hamil (Atikah dan Asfuah, 2010:177).

Hasil penelitian menunjukkan bahwa sebagian besar dari jumlah responden ibu hamil di Klinik Mitra Delima Kecamatan Banjarsari Kabupaten Ciamis pernah infeksi yaitu 36 orang $(56,3 \%)$. Ibu hami yang mengalami gizi kurang akan menurunkan daya tubuh rendah sehingga dapat dengan mudah terserang penyakit infeksi yang menyebabkan ibu hamil mengalami gizi kurang, pendarahan saat persalinan dan dapat menyebabkan cacingan dan saluran pencernaan berhubungan positif terhadap anemia (Syafiq, dkk,2014) .

Sebagian besar dari ibu di Klinik Mitra Delima Kecamatan Banjarsari Kabupaten Ciamis berpengetahuan kurang yaitu 34 orang $(53,1 \%)$. Pengetahuan merupakan 
salah satu faktor yang mempengaruhi terbentuknya perilaku kesehatan. Apabila ibu hamil mengetahui dan memahami akibat anemia dan cara mencegah anemia maka akan mempunyai perilaku keseha tan yang baik sehingga diharapkan dapat terhindar dari berbagai akibat atau risiko terjadinya anemia pada kehamilan. Perilaku yang demikian dapat berpengaruh terhadap penurunan kejadian anemia pada ibu hamil, (Soraya, 2013)

\section{SIMPULAN}

\section{Kesimpulan}

Berdasarkan hasil penelitian yang telah penulis lakukan tentang Gambaran Karakteristik Ibu Hamil Yang Mengalmi Anemia Di Klinik Mitra Delima Kecamatan Banjarsari Kabupaten Ciamis dapat penulis simpulkan sebagai berikut:

1. Sebagian besar dari ibu hamil di Klinik Mitra Delima Kecamatan Banjarsari Kabupaten Ciamis berumur beresiko yaitu 35 orang $(54,7 \%)$

2. Sebagian besar dari ibu hamil di Klinik Mitra Delima Kecamatan Banjarsari Kabupaten Ciamis mempunyai anak $>2$ (Multi) yaitu 37 orang $(57,8 \%)$

3. Sebagian besar dari ibu hamil di Klinik Mitra Delima Kecamatan Banjarsari Kabupaten Ciamis mempunyai jarak kehamilan $<2$ tahun yaitu 39 orang $(60,9 \%)$

4. Sebagian besar dari ibu hamil di Klinik Mitra Delima Kecamatan Banjarsari Kabupaten Ciamis berpendidikan dasar yaitu 35 orang $(54,7 \%)$

5. Sebagian besar dari ibu hamil di Klinik Mitra Delima Kecamatan Banjarsari Kabupaten Ciamis bekerja yaitu 35 orang $(54,7 \%)$

6. Sebagian besar dari ibu hamil di Klinik Mitra Delima Kecamatan Banjarsari
Kabupaten Ciamis mengalami KEK yaitu 34 orang $(53,1 \%)$

7. Sebagian besar dari jumlah responden ibu hamil di Klinik Mitra Delima Kecamatan Banjarsari Kabupaten Ciamis pernah infeksi yaitu 36 orang $(56,3 \%)$

8. Sebagian besar dari ibu di Klinik Mitra Delima Kecamatan Banjarsari Kabupaten berpengetahuan kurang yaitu 34 orang $(53,1 \%)$

\section{Saran}

1. Bagi Klinik Mtra Delima

Mengingat masih tingginya kejadian anemia pada ibu hamil sebanyak 60\% diharapkan petugas kesehatan dapat memberikan penyuluhan tentang cara pencegahan timbulnya anemia, baik berupa pola konsumsi yang baik dan cara menjaga kesehatan selama kehamilan serta optimalisasi ANC yaitu untuk meningkatkan kadar $\mathrm{Hb}$ ibu hamil dengan cara meningkatkan keptuhan konsumsi tablet Fe.

2. Bagi Petugas Kesehatan

Bagi Petugas Kesehatan khususnya bagi bidan agar lebih memperhatikan pola konsumsi dan pemeriksaan hemoglobin. Untuk memberikan penyuluhan yang intensif tentang kesehatan reproduksi khususnya mengenai umur ibu saat hamil. Bidan sangat berperan peting untuk menurunkan angka kejadian anemia dengan mendeteksi secara dini tentang pemeriksaan hemoglobin. Serta penyuluhan mengenai program pemberian tablet Fe. Hal ini bertujuan untuk menekan angka kejadian anemia pada ibu hamil.

3. Bagi Ibu Hamil

Ibu hamil dianjurkan rajin membaca buku KIA minimal2 kali dan mencari sumber informasi dari media cetak ( koran, majalah, dll) maupum elektronik ( televisi, radio, dll). Ibu yang bmempunyai pendidikan rendah 
sangat dianjurkan untuk mengikuti pelaksanaan penyuluhan selama 3 kali dalam kehamilan. Sehingga ibu mampu menerima informasi untuk melakukan pencegahan sebelum terjadinya anemia.

\section{DAFTAR PUSTAKA}

Dinas Kesehatan JABAR. Profil Kesehatan Tahun 2015. Dinas Kesehat Provinsi Jawa Barat. 2016; (Dinas Kesehatan JABAR):205

Manuaba, I.B.G, Ilmu Kebidanan, Penyakit Kandungan dan KB. EGC. Jakarta. 2012. 
Elsa Salsabila Amalia Nisa, Arifah Septiane, Siti Fatimah 